Published by Al-Nahrain College of Medicine P-ISSN 1681-6579

E-ISSN 2224-4719

Email: iraqijms@colmed-alnahrain.edu.iq

http://www.colmed-alnahrain.edu.iq

http://www.iraqijms.net

Iraqi JMS 2018; Vol. 16(1)

\title{
Post-operative Hypocalcemia among Ongoing Patients After Total and Subtotal Thyroidectomy
}

\author{
Raghad E. Naji $P h D$ \\ Dept. of biochemistry, Al-Kindy College of Medicine, University of Baghdad, Baghdad, Iraq
}

\begin{abstract}
Background Hypocalcemia is a major post-operative complication of total thyroidectomy, causing severe symptoms and increasing hospitalization time. The primary cause is secondary hypoparathyroidism following damage to or devascularization of one or more parathyroid gland during surgery.

Objective To identify the occurrence rate of post-operative hypocalcemia as an indicator of parathyroid gland function and its relation to the type of the surgical procedure of thyroidectomy whether it's a subtotal or total thyroidectomy.

Methods One hundred and ninety patients with total and subtotal thyroidectomy were selected in this study (144 females and 46 males). The patients were divided into 2 groups, group 1 (95 patients) represent the patients with total thyroidectomy, and group 2 (95 patients) represent the patients with subtotal thyroidectomy. Serum calcium and parathyroid hormone were done pre-operatively and post-operatively for all patients with a follow-up for serum calcium for 6 months.

Results Of the total number serum calcium levels decreased from pre-operative levels in 156 patients $(82 \%)$, but still within normal range $(2.1-2.6 \mathrm{mmol} / \mathrm{L})$. The overall incidence of transient hypocalcemia was $22 \%$ (42 patients), 35 patients belong to group 1 and 7 patients to group 2, and that of permanent hypocalcemia (hypocalcemia persisted at the 6 months assessment) was $2.6 \%$ (5 patients), 4 patients belong to group 1 and one patient to group 2. Most of the patients with hypocalcemia were asymptomatic $19.4 \%(n=37)$ and did not require calcium supplementation. Symptomatic hypocalcemia occurred in $5.2 \%(n=10)$ patients. It was found that the overall incidence of hypocalcemia after thyroidectomy was $24.7 \%$ (22\% transient and $2.6 \%$ permanent).

Conclusion It could be concluded that, insuring the integrity of parathyroid glands is important to avoid postthyroidectomy hypocalcemia. If incidental removal or devascularization of the parathyroid glands is noted, parathyroid auto-transplantation should be done.

Keywords Post-operative hypocalcemia, total thyroidectomy, subtotal thyroidectomy.

Citation Naji RE. Post-operative hypocalcemia among ongoing patients after total and subtotal thyroidectomy. Iraqi JMS. 2018; Vol. 16(1): 92-99. doi: 10.22578/IJMS.16.1.13
\end{abstract}

List of abbreviations: $M N G=$ Multi-nodular goiter, $\mathrm{pg}=$ pico gram, PTH = Parathyroid hormone, TNG = Toxic-nodular goiter

\section{Introduction}

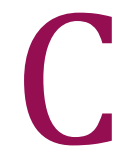
alcium regulation is essential for normal cell function in the human being. It plays an important role in neural transmission, membrane permeability, skeletal structure, and blood coagulation.
Approximately $99 \%$ of calcium is found in bone, and less than $1 \%$ is found in extracellular fluid. It is this extra-cellular calcium that is critical for normal physiological function.

Transitory hypocalcemia is one of the most common complication following thyroid surgery. The reported incidence ranges from 16.5 to $71 \%{ }^{(1,2)}$. 
Permanent hypocalcemia is less frequent following thyroidectomy, occurring in $1.5-1.8 \%$ (2).

The cause of post-surgery hypocalcemia is inadequate secretion of parathyroid hormone (PTH) by the parathyroid glands, results from direct injury to, devascularization of, or accidental removal of the parathyroid glands (3). Other possible causes are hemodilution, hypoalbuminemia, and changes in peripheral sensitivity to parathyroid hormone ${ }^{(4)}$.

Theodore Kocher recognized tetany as the main complication after thyroid surgery as early as 1883. Tetany was believed to be caused by hypothyroidism until Moussu (1898) could treated this condition with a parathyroid gland extract ${ }^{(5)}$.

Depending on the degree of parathyroid gland damage, hypocalcemia may be temporary lasting for few days to few months, or permanent, necessating lifelong oral calcium and vitamin D supplementation.

The immediate manifestations of hypocalcemia secondary to hypoparathyroidism are mostly neuromuscular symptoms including muscle cramps, tingling, circumoral and peripheral paresthesia, carpopedal spasm or tetany, seizures ${ }^{(6)}$.

Permanent symptomatic hypocalcemia is extremely distressing, it prolongs the hospital stay and it increases the cost of treatment, and causes substantial impact on patient's health (7).

Many studies have attempted to identify risk factors that will predict those patients who will develop post-thyroidectomy hypocalcemia thereby preventing significant morbidity and mortality.

In the last few decades few authors have examined the influence of the type of the surgical procedure of thyroidectomy on the incidence of post-operative hypocalcaemia ${ }^{(8,9)}$. The aim of current study is to evaluate the occurrence rate of post-operative hypocalcemia as an indicator of parathyroid gland function and its relation to the type of the surgical procedure of thyroidectomy whether it's a subtotal or total thyroidectomy.

\section{Methods}

This observational prospective study was done on patients undergone surgery for benign and malignant thyroid diseases between $1^{\text {st }}$ of January 2015 and $1^{\text {st }}$ of December 2016 at Alkindy Teaching Hospital by well-trained general surgeons.

During the study period, 190 consecutive patients undergone primary thyroid surgery were prospectively underwent analysis regarding post-operative parathyroid function. Of these, 144 (75.8\%) were females and 46 (24.2\%) were males with a female to male ratio of $3: 1$, median patients age was 42 years (range 24-65).

Informed consent to participate in this study were obtained and the study was approved by the Ethics Committee of Al-Kindy Teaching Hospital.

The following demographic data collected included age, gender, co-morbid conditions were defined. Other variables recorded included length of stay (LOS), and signs or symptoms of hypocalcemia, indication for surgery, histopathological results, presence or absence of thyroiditis.

Initial work up included a thorough clinical examination by specialized surgical team, biochemical analysis of thyroid hormones. Ultrasonography study of the thyroid gland and neck in general was done for all patients. Fine needle aspiration cytology was done for all patients with solitary nodules and those with nodules showing suspicious features of malignancy on clinical examination or ultrasound study. CT-scanning was done when there are clinical evidences of retrosternal extension.

Thyrotoxicosis was controlled preoperatively. Assessment of vocal cords mobility by indirect laryngoscopy prior to operation was done. Surgery was performed by well-trained surgical team under general anesthesia.

For analysis the patients were divided into two groups: group 1 patients who underwent total 
thyroidectomy, and group 2 patients who underwent subtotal thyroidectomy

Exclusion criterions were: (1) completion thyroidectomy following hemithyroidectomy, (2) concomitant radical/modified radical lymph node dissection, (3) patient with preexisting hypoparathyroidism, and (4) those who underwent parathyroid gland autotransplantation. Patients who underwent hemithyroidectomy were excluded as this operation is associated with a very low rate of post-operative hypocalcemia.

Serum calcium was estimated before commencing operation, and at $8 \mathrm{AM}$ on first postoperative days until discharge. PTH measurement was done for all patients.

Patients who developed hypocalcemia symptoms at early post-operative period were reviewed monthly for one year. Serum calcium and PTH were measured on monthly visit after stopping calcium treatment for 24 hours.

Post-operative hypocalcemia was diagnosed when serum calcium level of less than $2 \mathrm{mmol}$ /L (reference range 2.1-2.6 $\mathrm{mmol} / \mathrm{L}$ ) with or without obvious clinical features of hypocalcemia including paresthesia, muscle spasm or seizures.

Regarding PTH, values less than $15 \mathrm{pg} / \mathrm{mL}$ were considered low ${ }^{(10)}$.

Post-operative hypocalcemia is defined as a low calcium level persist for more than 6 months after thyroid surgery.

Indication for thyroid surgery was benign thyroid disease including simple goiter and thyrotoxic goiter, patients with various types of malignant thyroid tumors and patients with thyroiditis (11).

A standard approach was employed with a classical collar incision the parathyroid gland was identified macroscopically, and a meticulous dissection from the thyroid gland was performed, every effort was made to identify and preserve all parathyroid glands.

For all patients with mild post-operative hypocalcemia, oral calcium supplementation $500 \mathrm{mg}$ of oral calcium monocitrate (2 tablets three times daily) along with vitamin D analogue (Calcitriol $0.25 \mathrm{mg}$ ) twice daily independent of their clinical symptoms.

In severe symptomatic cases (patients with severe neuromuscular manifestations), intravenous calcium gluconate $10 \%$ three to six times daily according to clinical response.

Patients with postoperative hypocalcemia were discharged when their serum calcium levels higher than $2.0 \mathrm{mmol} / \mathrm{L}$. In these patients, levels of serum calcium and PTH were measured again within 2 weeks postoperatively after cessations of calcium and calcitriol substitution therapy for $24 \mathrm{hrs}$.

A final measurement of serum calcium and PTH level was performed 6 months after thyroidectomy. If serum calcium level returned to normal within 6 months, hypocalcemia was classified as transient; in all other cases, it was classified as permanent.

The following assays were employed in each laboratory investigation: chemiluminescence assay were used for detecting PTH (deferential values: $10-65 \mathrm{pg} / \mathrm{mL}$ ); total serum calcium was estimated by autoanalyzer method (normal range $2.1-2.6 \mathrm{mmol} / \mathrm{L}$ ).

\section{Statistical analysis}

Data processing and statistical analysis were done by using mini-tab V.16 processor.

\section{Results}

One hundred ninety patients who met the inclusion criteria were included in this study. Of these, 95 patients (50\%) were managed by total thyroidectomy (group 1) and 95 patients (50\%) were treated by subtotal thyroidectomy (group 2). There were 144 (75.8\%) females and $46(24.2 \%)$ males. The mean age was 46 years (range $27-68$ years).

Of the total number, serum calcium levels decreased from preoperative levels in 156 patients $(82 \%)$, but still within normal range (2.1- $2.6 \mathrm{mmol} / \mathrm{L}$ )

The overall incidence of transient hypocalcemia was 42 patients (22\%), 35 patients belong to group 1 and 7 patients to group 2, and that of permanent hypocalcemia (hypocalcemia persisted at the 6 months assessment) was 5 
patients (2.6\%), 4 patients belong to group 1 and 1 patient to group 2 .

Most of the patients with hypocalcemia were asymptomatic, $37(19.4 \%)$ and did not require calcium supplementation. Symptomatic hypocalcemia occurred in 10 (5.2\%) patients. Demographic and clinical characteristics of both groups are shown in Table 1.

Table 1. Incidence of postoperative hypocalcaemia in relation to different demographic and clinical variables $(\mathrm{N}=190)$

\begin{tabular}{|c|c|c|c|c|}
\hline \multicolumn{2}{|c|}{ Parameter } & $\begin{array}{c}\text { Total } \\
\text { No. (\%) }\end{array}$ & Group 1 & Group 2 \\
\hline \multirow{2}{*}{ Gender } & Male & $46(24.2 \%)$ & 23 & 23 \\
\hline & Female & $144(75.8 \%)$ & 72 & 72 \\
\hline \multirow{5}{*}{$\begin{array}{l}\text { Age at the time } \\
\text { of surgery }\end{array}$} & $20-29$ years & $28(14.7 \%)$ & 7 & 21 \\
\hline & 30-39 years & $85(44.7 \%)$ & 39 & 46 \\
\hline & $40-49$ years & $57(30.0 \%)$ & 33 & 24 \\
\hline & $50-59$ years & $16(8.4 \%)$ & 9 & 7 \\
\hline & $60-70$ years & $4(2.1 \%)$ & 2 & 2 \\
\hline \multirow{4}{*}{$\begin{array}{l}\text { Indication of } \\
\text { surgery }\end{array}$} & Benign disease & $70(36.8 \%)$ & 10 & 60 \\
\hline & Malignant disease & $34(17.9 \%)$ & 32 & 2 \\
\hline & Thyrotoxic disease & $65(34.2 \%)$ & 50 & 15 \\
\hline & Thyroiditis & $21(11.0 \%)$ & 3 & 18 \\
\hline
\end{tabular}

Hypocalcaemia was detected in the first postoperative day in 17 patients (8.9\%), 15 patients from group 1 and 2 from group 2, and delayed up to 3 rd postoperative day in 12 patients (6.3\%), 9 patients from group 1 and 3 from group 2 . details are shown in table 2.

Table 2. Time of onset of hypocalcemia in 47 patients with post-operative hypocalcemia

\begin{tabular}{cccc}
\hline \multirow{2}{*}{ Time } & \multicolumn{3}{c}{ No. of patients with hypocalcemia } \\
& Total & Group 1 & Group 2 \\
\hline $\mathbf{1}^{\text {st }}$ post-operative day & 17 & 15 & 2 \\
$\mathbf{2}^{\text {nd }}$ post-operative day & 8 & 6 & 2 \\
$\mathbf{3}^{\text {rd }}$ post-operative day & 4 & 3 & 1 \\
$\mathbf{4}^{\text {th }}$ post-operative day & 8 & 6 & 2 \\
$\mathbf{5}^{\text {th }}$ post-operative day & 6 & 4 & 2 \\
$\mathbf{6}^{\text {th }}$ post-operative day & 4 & 4 & 0 \\
\hline
\end{tabular}

On analyzing various clinical situations independently, both transient and permanent hypocalcemia were significantly associated with hyperthyroidism (Grave's disease and toxic nodular goiter (TNG)).
Thyroidectomy for thyroid gland malignancy was associated with high incidences of both transient and permanent hypocalcemia.

Among the 21 patients with classic form of thyroiditis (Hashimoto thyroiditis and 
lymphocytic thyroiditis), 3 patients (1.5\%) developed low calcium levels post-operatively, while 4 patients $(2.1 \%)$ from those with simple goiter developed post-operative hypocalcemia. Of all risk factors, total thyroidectomy was most likely to result in postoperative hypocalcemia than subtotal one.

Gender and patients age at the time of surgery also emerged as independent predictors of postoperative hypocalcemia.
Patients with 20-30 years group and those of 50-60 years age had significantly lower likelihoods of developing hypocalcemia postoperatively as shown in table 3 .

On average, patients undergoing thyroidectomy had a hospital length of stay of 1.9 days.

Table 3. Prevalence of hypocalcemia in different clinical and pathological situations

\begin{tabular}{|c|c|c|c|c|c|c|c|c|}
\hline \multirow{2}{*}{$\begin{array}{l}\text { Pathological } \\
\text { condition }\end{array}$} & \multirow{2}{*}{$\begin{array}{c}\text { No. of pts } \\
\text { with } \\
\text { hypocalcemia } \\
\text { /total }\end{array}$} & \multirow{2}{*}{$\begin{array}{c}\text { Mean S. Ca } \\
\mathrm{mmol} / \mathrm{L}\end{array}$} & \multirow{2}{*}{$\begin{array}{l}\text { Sex } \\
f / m\end{array}$} & \multicolumn{5}{|c|}{ Age groups (years) } \\
\hline & & & & $20-30$ & $30-40$ & $40-50$ & $50-60$ & $60-70$ \\
\hline Simple MNG & $4 / 70$ & 1.86 & $4 / 0$ & 1 & 1 & 1 & & 1 \\
\hline Toxic goiter & $19 / 65$ & 1.81 & $14 / 5$ & 1 & 9 & 9 & 1 & \\
\hline Malignancy & $21 / 34$ & 1.79 & $14 / 7$ & 1 & 11 & 7 & 1 & 1 \\
\hline Thyroiditis & $3 / 21$ & 1.79 & $2 / 1$ & & 1 & 1 & 1 & \\
\hline
\end{tabular}

Discussion

Postoperative hypocalcemia is a multifactorial, problematic source of morbidity for patients with thyroid surgery; resulting prolonged hospital stays with increase treatment costs (12).

Recently, many authors have advocated measurement of the PTH level several hours after operation in order to predict the development of hypocalcemia (13,14). The principle behind this, is that the half-life of PTH is 2 to 5 minutes (15); thus, the level of PTH in the immediate postoperative period, provides a very precise indication of parathyroid function. This practice has not been widely adopted ${ }^{(16)}$. However, the fast PTH assay is not available in the majority of the medical centers in our country.

In this study, serum calcium level was also analyzed as an indicator for hypoparathyroidism, furthermore, we analyze PTH level preoperatively and then one monthly just to ascertain that post-operative hypocalcemia is due to low level of PTH.
It was found that the overall incidence of hypocalcemia after thyroidectomy was $24.7 \%$ (22\% transient and $2.6 \%$ permanent).

Few authors had noted a $50 \%$ of transient and $4 \%$ permanent hypocalcemia following thyroidectomy ${ }^{(17,18) .}$

In this work, the incidence of permanent hypocalcemia appears low compared to some other comparable studies, this may be explained by the surgical technique we adopted (capsular dissection).

The current literature indicates that the incidence of hypocalcemia may be affected by a number of risk factors. The most important factor is the extent of surgery. More extensive thyroidectomy procedures, for instance, result in a greater incidence of hypocalcemia, though the exact mechanism behind the association is unclear ${ }^{(19)}$.

Study analysis demonstrates that, hypocalcemia occurred significantly more often after total thyroidectomy than after subtotal thyroidectomy. Incidental parathyroidectomy is believed by many authors to explain the increased incidence of hypocalcemia with more extensive surgery ${ }^{(20)}$. 
Post-operative hypocalcemia should clearly be considered in discussions about the appropriate extent of thyroid surgery. Particularly with total thyroidectomy procedure, surgeons may take corrective measures to reduce the incidence of hypocalcemia and improve long-term outcomes. For instance, if incidental removal or devascularization of the parathyroid glands is noted, parathyroid auto-transplantation should be done to reduce the occurrence of permanent hypocalcemia among those patients (21).

When performing a total thyroidectomy with central compartment dissection, the inferior parathyroid glands are at risk of vascular damage or even inadvertent removal during clearance of pre-tracheal and para-tracheal lymph-nodes in the median part of the neck (22). American Thyroid Association had revised the recommendation for central neck dissection and recommended prophylactic minimum dissection in selected patients only (23).

Blood supply of parathyroid glands was studied thoroughly by William Halsted as early as 1907 (24). The technique of capsular dissection of thyroid gland ensures intact parathyroid glands with its blood supply. Sosa et al. noted that lateral ligation of inferior thyroid arteries (ITA) as a strong predictor of hypocalcaemia (25).

Some authors suggest that a surgeon's skill and experience affect the incidence of postthyroidectomy hypocalcemia. However, one study found that patients operated on by surgical trainees had complications that were comparable to patients operated on by welltrained consultant surgeons ${ }^{(26)}$.

In accordance with our findings, Cheah et al. (27) found that a greater proportion of the women in their study were affected by thyroid disease, but that there was no association between patient sex and hypoparathyroidism. The association between postoperative hypocalcemia and female gender also found in the literature may be due to women being more prone to calcium and vitamin D deficiency than men ${ }^{(28)}$.

The incidence of hypocalcemia is relatively more common after thyroidectomy for thyrotoxicosis. This finding was observed by Michie and colleagues as early as 1965 (29).

Hypocalcemia was observed in some earlier studies associated with Grave's disease as noticed in some previous studies $(28,30)$.

McHenry (31) found a strong association between post-thyroidectomy hypocalcemia and Graves' disease and explain this relationship by that the location and preservation of the parathyroid glands in patients with Graves' disease is more difficult. This is also in consistent with our finding in the present study.

Hyperthyroidism may lead to demineralization of bone. Transient hypocalcaemia may be related to osteodystrophy seen in thyrotoxicosis. Furthermore, surgical manipulation may cause thrombosis of parathyroid vessels due to autoimmune process of Grave's disease (32).

The results of present analysis demonstrate that, the incidence of hypocalcemia following thyroid surgery is more commonly associated with total thyroidectomy especially for malignant conditions Zedenus et al. ${ }^{(32)}$ support our finding, the possible explanation is that the surgery in malignant disease is more extensive and more difficult due to adhesion, fibrosis of the thyroid tissues comparing with benign disease.

Finding of this study regarding the higher incidence of hypocalcemia among thyroid cancer patients is consistent with previous studies (33), who believe that malignancy is usually treated with a more aggressive approach to thyroid surgery, thereby leading to incidental damage or removal of the parathyroid gland and hypocalcemia.

The current study concluded that a more aggressive approach to thyroid surgery, leading to incidental damage or removal of the parathyroid gland with subsequent hypocalcemia. On the other hand, refined 
surgical approach may decrease the incidence of hypocalcemia following thyroid surgery.

Preservation of parathyroid glands and its blood supply is essential to avoid this complication. If incidental removal or devascularization of the parathyroid glands is noted, parathyroid auto-transplantation should be done.

\section{Acknowledgments}

Special thanks to the surgical department, AlKindy Teaching Hospital, Baghdad, Iraq.

\section{Conflict of interest}

The author has no conflict of interest to declare.

\section{Funding}

The author completes the work without any funding resources.

\section{References}

1. Bhattacharyya N, Fried MP. Assessment of the morbidity and complications of total thyroidectomy. Arch Otolaryngol Head Neck Surg. 2002 Apr;128(4):389-92. doi: 10.1001/archotol.128.4.389.

2. Thomusch $O$, Machens $A$, Sekulla $C$, et al. The impact of surgical technique on postoperative hypoparathyroidism in bilateral thyroid surgery: a multivariate analysis of 5846 consecutive patients. Surgery. 2003; 133(2): 180e5. doi: $10.1067 / \mathrm{msy} .2003 .61$.

3. McHenry CR, Speroff $T$, Wentworth $D$ et al. Risk factors for postthyroidectomy hypocalcemia. Surgery. 1994; 116(4): 641e7; discussion 647e8.

4. Mehta N, Watts NB, Welge JA, et al. Comparison of Serum calcium change following thyroid and nonthyroid neck surgery. Otolaryngol Head Neck Surg. 2006; 134(6): 901-6. doi: http://doi.org/10.1016/j.otohns.2006.02.021.

5. Wade JS, Fourman P, Deane L. Recovery of parathyroid function in patients with transient hypoparathyroidism after thyroidectomy. $\mathrm{Br} \mathrm{J}$ Surg. 1965; 52 (7): 493-6.

6. Marohn MR, LaCivita KA. Evaluation of total/near total thyroidectomy in a short-stay hospitalization; safe and cost-effective. Surgery. 1995; 118(6): 943-7; discussion 947-8.

7. Bergenfelz A, Jansson $S$, Kristoffersson $A$, et al. Complications to thyroid surgery: results as reported in a database from a multicenter audit comprising 3,660 patients. Langenbecks Arch Surg. 2008; 393(5): 667-73. doi: 10.1007/s00423-008-0366-7.

8. Del Rio $P$, Arcuri MF, Ferreri $G$, et al. The utility of serum PTH assessment 24 hours after total thyroidectomy. Otolaryngol Head Neck Surg. 2005; 132(4): 584-6. doi: 10.1016/j.otohns.2005.01.009.

9. Quiros RM, Pesce CE, Wilhelm SM, et al. Intraoperative parathyroid hormone levels in thyroid surgery are predictive of postoperative hypoparathyroidism and need for vitamin D supplementation. Am J Surg. 2005; 189(3): 306-9. doi: 10.1016/j.amjsurg.2005.01.006.

10. Roof BS, Piel CF, Hansen I, et al. Serum parathyroid hormone levels and serum calcium levels from birth to senescent. Mech Aging Dev. 1976; 5(4): 289-304.

11. Monaco F. Classification of thyroid disease: suggestion for a revision. J Clin Endocrinol Metab. 2003; 88(4): 1428-32. doi: 10.1210/jc.2002-021260.

12. Baldassarre RL, Chang DC, Brumund $K T$, et al. Predictors of hypocalcemia after thyroidectomy: results from the Nationwide Inpatient sample. ISRN Surg. 2012; 2012: 838614. doi: $10.5402 / 2012 / 838614$.

13. Lindblom $P$, Westrdahl J, Bergenfelz A. Low parathyroid hormone levels after thyroid surgery a feasible predictor of hypocalcemia. Surgery. 2002; 131(5): 515-20.

14. Luu $Q$, Andersen PE, Adams J, et al. The predictive value of perioperative calcium levels after thyroid/parathyroid surgery. Head Neck. 2002; 24(1): 63-7. doi:10.1002/hed.10013.

15. Lombardi CP, Raffaelli $M$, Princi $P$, et al. Early prediction of post-thyroidectomy hypocalcemia by one single iPTH measurement. Surgery. 2004; 136(6): 1236-41. doi: 10.1016/j.surg.2004.06.053.

16. Wiseman JE, Mossanen $\mathrm{M}$, Ituarte $\mathrm{PH}$, et al. An Algorithm informed by the parathyroid hormone level reduces hypocalcemic complications of thyroidectomy. World J surg. 2010; 34(3): 532-7. doi: 10.1007/s00268-009-0348-0.

17. Shaha AR, Jaffe BM. Parathyroid preservation during thyroid surgery. Am J Otolaryngol. 1998; 19(2): 113-7.

18. Delbridge L, Guinea Al, Reeve TS. Total thyroidectomy for bilateral benign multinodular goiter, effect of changing practice. Arch Surg. 1999; 134(2): 1389-93. doi: 10.1001/archsurg.134.12.1389.

19. Ozbas S, Kocak S, Aydintug S, et al. Comparison of the complications of subtotal, near total and total thyroidectomy in the surgical management of multinodular goiter. Endocr J. 2005; 52(2): 199-205.

20. Karamanakos SN, Markou KB, Panagopoulos K, et al. Complications and risk factors related to the extent of surgery in thyroidectomy. Results from 2,043 procedures. Hormones (Athens). 2010; 9(4): 318-25.

21. Reeve T, Thompson NW. Complications of thyroid surgery: how to avoid them, how to manage them, and observations on their possible effect on the whole patient. World J Surg. 2000; 24(8): 971-5.

22. Chisholm EJ, Kulinskaya E, Tolley NS. Systematic review and meta-analysis of the adverse effects of thyroidectomy combined with central neck dissection as compared with thyroidectomy alone. 
Laryngoscope. 2009; 119(6): 1135-9. doi: 10.1002/larg.20236.

23. American Thyroid Association (ATA) Guidelines Taskforce on Thyroid Nodules and Differentiated Thyroid Cancer1, Cooper DS, Doherty GM, et al. Revised American Thyroid Association Management Guidelines for patients with thyroid nodules and differentiated thyroid cancer. Thyroid. 2009; 19(11): 1167-214. doi: 10.1089/thy.2009.0110.

24. Erbil $Y$, Barbaros $U$, Temel $B$, et al. The impact of age, vitamin D3 level, and incidental parathyroidectomy on postoperative hypocalcemia after total or near total thyroidectomy. Am J Surg. 2009; 197(4): 43946. doi: 10.1016/j.amjsurg.2008.01.032.

25. Sosa JA, Mehta PJ, Wang TS, et al. Racial disparities in clinical and economic outcomes from thyroidectomy. Ann Surg. 2007; 246(6): 1083-91. doi: 10.1097/SLA.0b013e31812eecc 4.

26. Sosa JA, Bowman HM, Tielsch JM, et al. The importance of surgeon experience for clinical and economic outcomes from thyroidectomy. Ann Surg. 1998; 228(3): 320-30.

27. Cheah WK, Arici C, Ituarte PH, et al. Complications of neck dissection for thyroid cancer. World J Surg. 2002; 26(8): 1013-6. doi: 10.1007/s00268-002-66704.

28. Pesce CE, Shiue Z, Tsai HL, et al. Postoperative hypocalcemia after thyroidectomy for Graves' disease. Thyroid. 2010; 20(11): 1279-83. doi: 10.1089/thy.2010.0047.

29. Michie W, Stowers JM, Frazer SC, et al. Thyroidectomy and the parathyroids. Br J Surg. 1965; 52: 503-14.

30. Gann DS, Paone JF. Delayed hypocalcemia after thyroidectomy for Graves' disease is prevented by parathyroid autotransplantation. Ann Surg. 1979; 190(4): 508-13.

31. McHenry CR. "Same-day" thyroid surgery: an analysis of safety, cost savings, and outcome. Am Surg. 1997; 63(7): 586-9; discussion 589-90.

32. Zedenus J, Wadstorm C, Delbridge L. Routine autotransplantation of at least one parathyroid gland during total thyroidectomy may reduce permanent hypoparathyroidism to zero. Aust NZ J Surg. 1999; 69(11) 794-7.

doi: 10.1046/j.1440.1622.1999.01697.x.

33. Qasaimeh GR, Al Nemri S, Al Omari AK. Incidental extirpation of the parathyroid glands at thyroid surgery: risk factors and post-operative hypocalcemia Eur Arch Otorhinolaryngol. 2011; 268(7): 1047-51. doi: 10.1007/s00405-010-1413-x.

\section{E-mail: ragademadnaji@gmail.com}

Received Jun. $1^{\text {st }} 2017$

Accepted Nov. 29 2017 